\title{
Agrobiodiversidade e etnoconhecimento na Gleba Nova Olinda I, Pará: interações sociais e compartilhamento de germoplasma da mandioca (Manihot esculenta Crantz, Euphorbiaceae) Agrobiodiversity and ethnoknowledge in Gleba Nova Olinda I, Pará: social interactions and sharing of manioc's germplasm (Manihot Esculenta Crantz, Euphorbiaceae)
}

\author{
Pedro Glécio Costa Lima', Regina Oliveira da Silva', Márlia Regina Coelho-Ferreira', \\ Jorge Luis Gavina Pereira! \\ 'Museu Paraense Emílio Goeldi/MCTI. Belém, Pará, Brasil
}

\begin{abstract}
Resumo: Compreender as relações sociais que favorecem a ocorrência e a ampliação da diversidade biológica na região neotropical vem sendo uma das principais preocupações da etnobiologia. Este trabalho objetivou avaliar a riqueza de etnovariedades de mandioca cultivadas em comunidades situadas na área de floresta pública estadual denominada Gleba Nova Olinda I, Pará, Brasil. Os dados foram obtidos durante oficinas participativas com 46 informantes, os quais foram submetidos a análises qualitativas e quantitativas. No local, são conhecidas pelo menos 52 etnovariedades de mandioca, cujo compartilhamento de germoplasma ocorre de forma inter e intracomunitária. O acúmulo de conhecimento detido pelos comunitários sobre esse recurso agrobiológico revela o protagonismo da população na conservação biológica na região da Gleba Nova Olinda I. Desta maneira, é importante que o apoio ao desenvolvimento local esteja calcado na valorização do etnoconhecimento.
\end{abstract}

Palavras-chave: Agrobiodiversidade. Etnoconhecimento. Etnobotânica.

\begin{abstract}
A major concern of ethnobiology is to understand the social relations that favor the occurrence and expansion of biological diversity in the Neotropic. This article evaluates the richness of ethnovarieties of cassava cultivated in communities located in public forest lands named Gleba Nova Olinda I, Pará State, Brazil. Data were obtained in workshops with 46 informants, and were analyzed by qualitative and quantitative methods. There are at least 52 manioc ethnovarieties on this site and germplasm sharing occurs both inside and outside the community. The knowledge improvement on this agrobiological resource by community members shows the important role that the inhabitants play in biological conservation of Gleba Nova Olinda I. Thus, support to local development should be grounded on ethnoknowledge.
\end{abstract}

Keywords: Agrobiodiversity. Ethnoknowledge. Ethnobotany.

\footnotetext{
LIMA, Pedro Glécio Costa; OLIVEIRA, Regina; COELHO-FERREIRA, Márlia Regina; PEREIRA, Jorge Luis Gavina. Agrobiodiversidade e etnoconhecimento na Gleba Nova Olinda I, Pará: interações sociais e compartilhamento de germoplasma da mandioca (Manihot esculenta Crantz, Euphorbiaceae). Boletim do Museu Paraense Emílio Goeldi. Ciências Humanas, v. 8, n. 2, p. 419-433, maio-ago. 2013. Autor para correspondência: Pedro Glécio Costa Lima. Museu Paraense Emílio Goeldi/MCTI. Coordenação de Botânica. Av. Perimetral, 1901 - Terra Firme. Belém, PA, Brasil. CEP 66077-530 (gleciolima@gmail.com).
}

Recebido em 23/06/2012

Aprovado em 25/06/2013

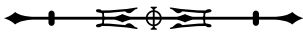




\section{INTRODUÇÃO}

Chegando a receber o título de 'pão do Brasil' (EMBRAPA, 2005; Adams et al., 2008), a mandioca (Manihot esculenta Crantz, Euphorbiaceae), de fato, é uma das principais espécies que compõem a agrobiodiversidade deste país, desempenhando papel chave na dieta de diversas comunidades (Adams et al., 2008). Tendo como importante centro de cultivo a região amazônica, onde está documentado um grande número de etnovariedades (Chernela, 1986; Faraldo et al., 2000; Emperaire, 2002), a importância desta espécie vai além dos aspectos relacionados à segurança alimentar, estando intimamente ligada às práticas culturais de diversos grupos sociais amazônicos, incluindo desde os habitantes mais antigos, os indígenas (Kerr e Clement, 1980; Chernela, 1986; Emperaire e Peroni, 2007; Heckler e Zent, 2008; Robert et al., 2012), até os grupos de ocupação mais recente, como seringueiros, caboclos, agricultores e colonos de assentamentos rurais (Amorozo, 2000; Emperaire, 2002; Emperaire e Peroni, 2007; Fraser, 2010).

Apesar da diminuição de 4,7\% na produção, entre os anos de 2009 e 2010, o cultivo da mandioca mantémse como atividade expressiva na paisagem agrícola amazônica, alcançando, em 2010, uma produção de 6.810.636 toneladas (IBGE, 2012). Trata-se do principal produto de lavoura temporária na Amazônia. Pensar na conservação do patrimônio genético desta espécie requer o reconhecimento do papel das comunidades tradicionais, principais guardiães de recurso biológico, atuando ainda na própria ampliação da diversidade genética (Emperaire, 2005; Emperaire e Peroni, 2007; Nassar, 2007). No entanto, os grupos sociais que detêm a carga cultural com potencial para apoio e implementação da conservação de recursos genéticos de mandioca passam a sofrer limitações ao fortalecimento de seus sistemas produtivos e de reprodução cultural. Por exemplo, a questão fundiária ainda é o principal empecilho e promove a instabilidade dessas comunidades. Outros fatores que oferecem ameaças à agricultura tradicional são o avanço da exploração madeireira ilegal, a ampliação de projetos hidrelétricos e o desestímulo em permanecer nas atividades produtivas.

No contexto dos saberes destes atores, a agrobiodiversidade vem a ser uma riqueza cultural resultante das interações humanas com os recursos naturais no bioma onde estão inseridas, com produtos e estilos de vida que promovem a continuidade de uma paisagem favorável à sua sobrevivência e reprodução cultural. $\mathrm{Na}$ Convenção sobre a Diversidade Biológica (CDB), a valorização do etnoconhecimento e da diversidade biológica, associada a conhecimentos tradicionais, foi estabelecida como estratégica (ONU, 1992). Passados 20 anos, a conservação da agrobiodiversidade no Brasil carece de superar desafios para a real visibilidade de ações para as comunidades. Além do mais, a própria definição da agrobiodiversidade é reconhecida como algo ainda em construção (Santilli, 2009).

Procurando contribuir para a reflexão sobre a importância da inclusão de produtores agroextrativistas nas estratégias de conservação agrobiológica, este artigo tem como objetivo estimar a riqueza de etnovariedades de mandioca cultivadas pelos comunitários nos roçados da Gleba Nova Olinda I, estado do Pará, Brasil. Foram incluídas análises sobre os critérios utilizados pelos comunitários para a diferenciação das etnovariedades, bem como as estratégias locais para o compartilhamento de recursos genéticos da planta. Informações desta natureza devem ser multiplicadas na produção científica regional, no sentido de balizar ações adequadas à conservação agrobiológica.

\section{MATERIAL E MÉTODOS}

\section{ÁREA DE ESTUDO}

O estudo foi desenvolvido na Gleba Nova Olinda I, localizada nos municípios de Santarém e Juruti, oeste do estado do Pará (Figura 1). Esta gleba possui, aproximadamente, 173 mil hectares, abrangendo 14 comunidades ribeirinhas, compostas por populações

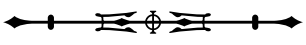




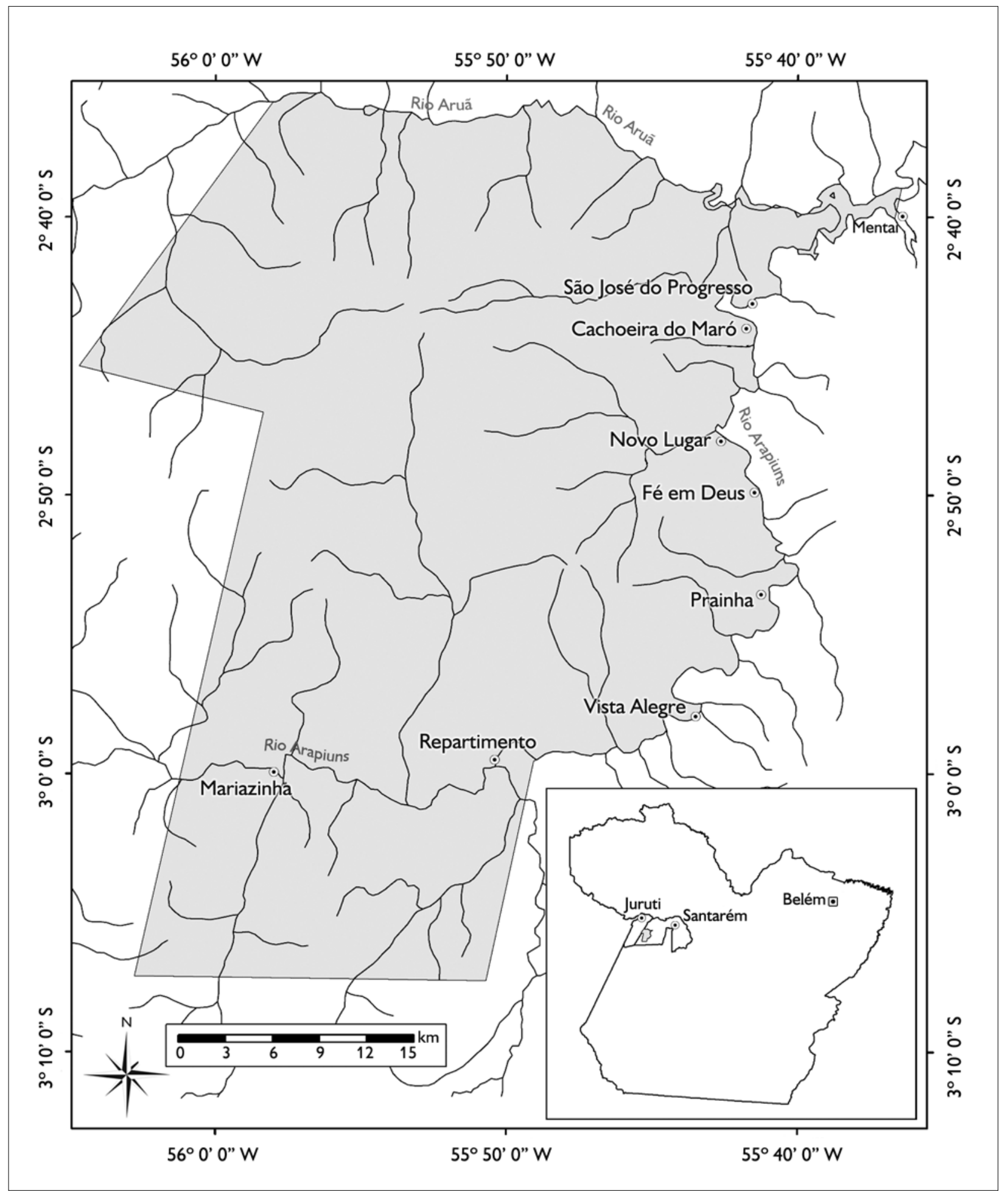

Figura 1. Localização das comunidades Fé em Deus, Mariazinha, Novo Lugar, Prainha, Repartimento, São José do Progresso e Vista Alegre. Gleba Nova Olinda I, estado do Pará, Brasil. 
tradicionais, indígenas e não indígenas, com 309 famílias, formando uma população de 1.304 pessoas.

A Gleba situa-se à margem direita do rio Aruã e à margem esquerda do rio Maró, em uma distância de, aproximadamente, $93 \mathrm{~km}$ em linha reta da sede do município de Santarém. Apesar de o processo de asseguração dos direitos comunitários sobre a terra estar em andamento por meio da criação de Projetos de Assentamentos Agroextrativistas (PAE), a região apresenta conflitos fundiários devido à pressão do setor madeireiro, envolvendo lotes inseridos em áreas comunitárias (Pará, 2009). As comunidades Novo Lugar, São José do Progresso e Cachoeira do Maró reivindicam o reconhecimento de território indígena, com área em torno de 42.373 ha, denominado Terra Indígena Maró, caracterizado como de ocupação tradicional permanente dos povos indígenas Borari e Arapium, ligados por relações de parentesco e redes de reciprocidade (FUNAI, 2011).

Trata-se de uma área com várias tipologias vegetacionais, onde predomina a floresta equatorial subperenifólia, ocorrendo ainda o cerrado equatorial subperenifólio. Como é comum na bacia amazônica, ocorrem, nesta região, as florestas sujeitas à inundação, que, neste caso, são florestas equatoriais higrófilas e campos equatoriais higrófilos (Pará, 2009).

A problemática estabelecida nesta região exigiu do governo do estado do Pará a conformação de ações frente às demandas específicas das comunidades, resultando no Projeto de Desenvolvimento Comunitário: fortalecimento da economia agroflorestal e extrativista das comunidades na Gleba Nova Olinda I, com o intuito de apresentar propostas para projetos de desenvolvimento comunitário com bases sustentáveis, permitindo a essas comunidades usufruir da biodiversidade local e melhorar sua qualidade de vida (Pará, 2009). De acordo com os dados do relatório do referido projeto, a população das comunidades varia de 55 a 174 habitantes, a maioria nascida na própria localidade onde reside; quando não, os moradores são advindos de outras comunidades rurais de Santarém e de municípios vizinhos. Cerca de 70\% são católicos, 22\% são evangélicos e $8 \%$ não declararam religião. Com relação ao gênero, $48 \%$ são mulheres e $52 \%$ homens. A educação formal é uma das principais carências da região. A maioria das escolas oferece o ensino até a oitava série, sendo poucos os jovens que estão cursando ou concluíram o nível médio.

A caracterização das áreas de uso dos recursos naturais, realizada pelos comunitários, faz menção a três principais tipos de ambiente: as florestas, os roçados e os quintais. As principais atividades econômicas e de subsistência são agricultura, caça, pesca, extrativismo e pequenas criações. Os recursos utilizados pelos comunitários estão sujeitos à variação temporal quanto à disponibilidade no decorrer do ano, o que é comum em atividades agroextrativistas.

A agricultura apresenta-se como atividade essencial para a segurança alimentar, além de contribuir para a estabilidade no ingresso de renda na economia familiar ao longo do ano. Quanto ao extrativismo, a maioria dos produtos é explorada no período do inverno amazônico, o qual corresponde aos primeiros meses do ano. Importantes frutíferas que fazem parte da base alimentar local, como o açaí (Euterpe oleracea Mart.), patauá (Oenocarpus bataua Mart.), taperebá (Spondias mombin L.) e castanha-do-pará (Bertholletia excelsa Bonpl.), apresentam a produção nesta época. No período menos chuvoso, as frutíferas disponíveis são as palmeiras tucumã (Astrocaryum vulgare Mart.) e buriti (Mauritia flexuosa L. f.).

Outros recursos, como fibras, cascas e madeira, são coletados ao longo do ano e integram a renda familiar nestas comunidades. Apesar de existir um escoamento local da produção, os principais vínculos comerciais dessas comunidades estão estabelecidos com os centros urbanos dos municípios de Santarém e Juruti, de forma direta e por intermédio de atravessadores.

\section{COLETA DOS DADOS}

Os dados referentes à agrobiodiversidade e ao etnoconhecimento da mandioca foram obtidos durante o trabalho de campo e as oficinas realizadas junto aos comunitários do Projeto Fortalecimento da Economia

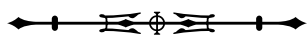


Agroflorestal e Extrativista das Comunidades na Gleba Nova Olinda I - Pará.

Durante as oficinas para o mapeamento participativo dos recursos agroextrativistas, foram realizadas entrevistas, por meio de conversas informais e visitas a alguns roçados, o que permitiu a obtenção dos dados sobre as etnovariedades de mandioca cultivadas por moradores das comunidades Cachoeira do Maró, Fé em Deus, Mariazinha, Novo Lugar, Prainha, Repartimento, São José do Progresso e Vista Alegre, todas localizadas no rio Maró. Foram inseridos dados relacionados à comunidade Mentai, localizada fora dos limites da Gleba, mas citada como colônia agrícola em passado recente e como distribuidora de mandioca. No total, participaram 15 mulheres e 31 homens, entrevistados individualmente ou em casais. Foram anotados os nomes das etnovariedades e os atributos utilizados por cada informante para diferenciá-las, a origem das mandiocas e histórias de vida.

Os dados foram organizados em tabelas e analisados por meio de métodos da estatística descritiva, com sínteses apresentadas na forma de gráficos e tabelas. A riqueza de etnovariedades foi analisada por meio da curva de rarefação, que consiste em calcular o número esperado de etnovariedades em cada amostra para um tamanho de amostra padrão (Peroni et al., 2008). Para a aplicação na etnobotânica, considera-se o número de citações em cada entrevista que compõe a amostra (Hanazaki et al., 2000). A curva de rarefação foi gerada por meio do programa Estimate Swin 8.20.

\section{RESULTADOS E DISCUSSÃO}

\section{RIQUEZA DE ETNOVARIEDADES}

Pelo menos 52 etnovariedades de mandioca são cultivadas e multiplicadas nos diversos roçados mantidos pelos moradores das comunidades estudadas (Tabela 1). Diferentemente de outras regiões do Brasil, nestas localidades, assim como em outras no estado do Pará, não são empregados os termos 'mandioca doce' e 'brava', mas 'mandioca', para as variedades tóxicas, e 'macaxeira' para as variedades com baixa concentração de ácido cianídrico, componente que confere toxidade à planta. A riqueza de etnovariedades é diferentemente distribuída entre as comunidades. Prainha e Vista Alegre destacamse, apresentando 24 e 23 etnovariedades de mandioca, respectivamente. A etnovariedade Sardinha obteve maior número de citações $(n=35)$ e é uma das mais populares, sendo cultivada na maioria das comunidades $(n=8)$. A etnovariedade Coraci é a segunda mais citada (32), porém ocorre em todas as comunidades $(n=9)$. A riqueza média por comunidade foi de 13,33 $\pm 8,32$, enquanto a riqueza média por agricultor foi de 5,97 $\pm 3,23$. A riqueza de etnovariedades observada em trabalhos realizados na Amazônia coloca os resultados deste estudo em evidência em razão de sua relevância para a conservação agrobiológica. Considerando tais trabalhos, observam-se valores que variam de 40 a 137 etnovariedades. Os resultados que superam o presente trabalho são de Chernela (1986), 137; Heckler e Zent (2008), 113; Emperaire (2000), 66; e Lima et al. (2012), 54. Enquanto que os valores inferiores são de Robert et al. (2012), 47; e Kerr e Clement (1980), 40.

A curva de rarefação não alcançou uma estabilização, sugerindo que, possivelmente, mais etnovariedades possam ser documentadas em novos levantamentos para essa região, principalmente em função do constante fluxo de material genético resultante da rede de troca estabelecida entre os comunitários (Figura 2). A atual diversidade de etnovariedades deve ser encarada como um resultado sujeito a variações, uma vez que modificações nos roçados são recorrentes e necessárias. Os roçados são espaços de experimentação do agricultor para a obtenção de rentabilidade e qualidade agronômicas adequadas aos seus anseios produtivos (farinha, goma, tucupi), incluindo etnovariedades geralmente com ciclos produtivos heterogêneos, indo desde as precoces (seis meses) até algumas de ciclos maiores (mais de 12 meses). De acordo com Lima et al. (2012), essa dinâmica confere oscilações na riqueza varietal, podendo ser ampliada ou reduzida nos

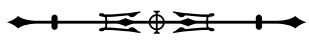


Tabela 1. Etnovariedades de mandioca cultivadas em roçados de comunidades da Gleba Nova Olinda I, estado do Pará, Brasil.

(Continua)

\begin{tabular}{|c|c|c|c|}
\hline \multicolumn{2}{|c|}{ Referencial para nomeação } & Etnovariedade & Total de citações \\
\hline \multirow{14}{*}{ Recursos da fauna } & \multirow{4}{*}{ Ave } & Goela de jacu & 1 \\
\hline & & Inambu & 7 \\
\hline & & Papagaio & 1 \\
\hline & & Passarinho & 4 \\
\hline & Mamífero & Cavalo & 2 \\
\hline & \multirow{7}{*}{ Peixe } & Acari & 1 \\
\hline & & Jaraqui & 19 \\
\hline & & Jaraqui amarelo & 1 \\
\hline & & Jaraqui preto & 2 \\
\hline & & Piaba & 5 \\
\hline & & Sardinha & 35 \\
\hline & & Tambaqui & 4 \\
\hline & هuelônin & Jabuti & 2 \\
\hline & & Tartaruguinha & 2 \\
\hline \multirow{6}{*}{ Recursos da flora } & Árvore & Munguba & 2 \\
\hline & \multirow{5}{*}{ Palmeira } & Açaí & 1 \\
\hline & & Buriti & 1 \\
\hline & & Inajá & 2 \\
\hline & & Inajazinho & 9 \\
\hline & & Tucumã & 2 \\
\hline \multirow{16}{*}{ Outros } & \multirow{4}{*}{ Forma da planta } & Atrapalhadinha & 7 \\
\hline & & Baixinha & 4 \\
\hline & & Brebezolhuda & 6 \\
\hline & & Caroço & 8 \\
\hline & \multirow{10}{*}{ Atributos organolépticos (cor) } & Douradinha & 1 \\
\hline & & Guia-roxa & 1 \\
\hline & & Pingo de ouro & 1 \\
\hline & & Preta & 8 \\
\hline & & Pretinha & 1 \\
\hline & & Pretona & 4 \\
\hline & & Roxa & 1 \\
\hline & & Roxinha & 1 \\
\hline & & Vermelha & 1 \\
\hline & & Vermelhinha & 1 \\
\hline & \multirow{2}{*}{ Outro } & Achada & 19 \\
\hline & & Arrouba & 2 \\
\hline
\end{tabular}




\begin{tabular}{|c|c|c|c|}
\hline \multicolumn{2}{|c|}{ Referencial para nomeação } & Etnovariedade & Total de citações \\
\hline \multirow{15}{*}{ Outros } & \multirow{12}{*}{ Outro } & Brebe & 4 \\
\hline & & Cadete & 3 \\
\hline & & Coraci & 32 \\
\hline & & Fruta & 1 \\
\hline & & Macaxeira & 1 \\
\hline & & Manicuera & 7 \\
\hline & & Manteiga & 13 \\
\hline & & Manteiguinha & 7 \\
\hline & & Milagrosa & 1 \\
\hline & & Pinajé & 6 \\
\hline & & Seis meses & 3 \\
\hline & & Tauá & 2 \\
\hline & \multirow{3}{*}{ Procedência } & Maria Augusta & 3 \\
\hline & & São José & 10 \\
\hline & & Xingu & 1 \\
\hline Total & & 51 & 263 \\
\hline
\end{tabular}

roçados devido aos processos de manutenção, incorporação e abandono de variedades feitos pelos agricultores.

A nomeação das etnovariedades é baseada em diversos referenciais do imaginário local. Conforme os exemplos apresentados na Tabela 2 , a riqueza de detalhes na descrição de algumas etnovariedades expressa o valor cultural desta espécie para as comunidades. Os caracteres morfológicos e organolépticos (cores de diversas estruturas vegetais) são os principais atributos utilizados pelos agricultores para particularizar cada tipo de mandioca. Em algumas nomeações, são associados a recursos da fauna e da flora local. A procedência do material (local ou fornecedor) também é referencial para classificar algumas etnovariedades obtidas fora da comunidade.

Para o entendimento dos comentários locais sobre a descrição das etnovariedades, os termos da morfologia da mandioca apresentam as seguintes expressões botânicas, correspondentes nas descrições presentes na Tabela 2: as cicatrizes da inserção da folha no caule podem ser nomeadas de 'olho', 'nó' ou 'caroço'; o pecíolo foliar é chamado de 'bracinha'; o tubérculo é chamado de 'batata', 'raiz' ou 'maniva'; o caule ou a seção utilizada para o cultivo é a 'maniva' ou 'pau'; a planta como um todo às vezes é definida como 'árvore', principalmente quando descrevem características gerais de sua estrutura e porte. As mandiocas mais produtivas são qualificadas como 'rendosas', sendo este termo muito comum nos comentários sobre as etnovariedades citadas.

A caracterização e a diferenciação das etnovariedades pelos comunitários levam em conta como principais elementos a coloração da batata (polpa dos tubérculos), a coloração do caule e as características das folhas (largura do limbo foliar e coloração do pecíolo) (Figura 3). O porte da planta e o padrão das ramificações também são elementos que chamam a atenção dos comunitários.

A coloração do tubérculo desponta como atributo principal não por acaso. Por influenciar no valor de mercado da farinha produzida, a coloração determinará se o produto poderá ser mais ou menos atraente. Nesta região, a coloração amarela é um atributo favorável ao

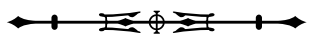




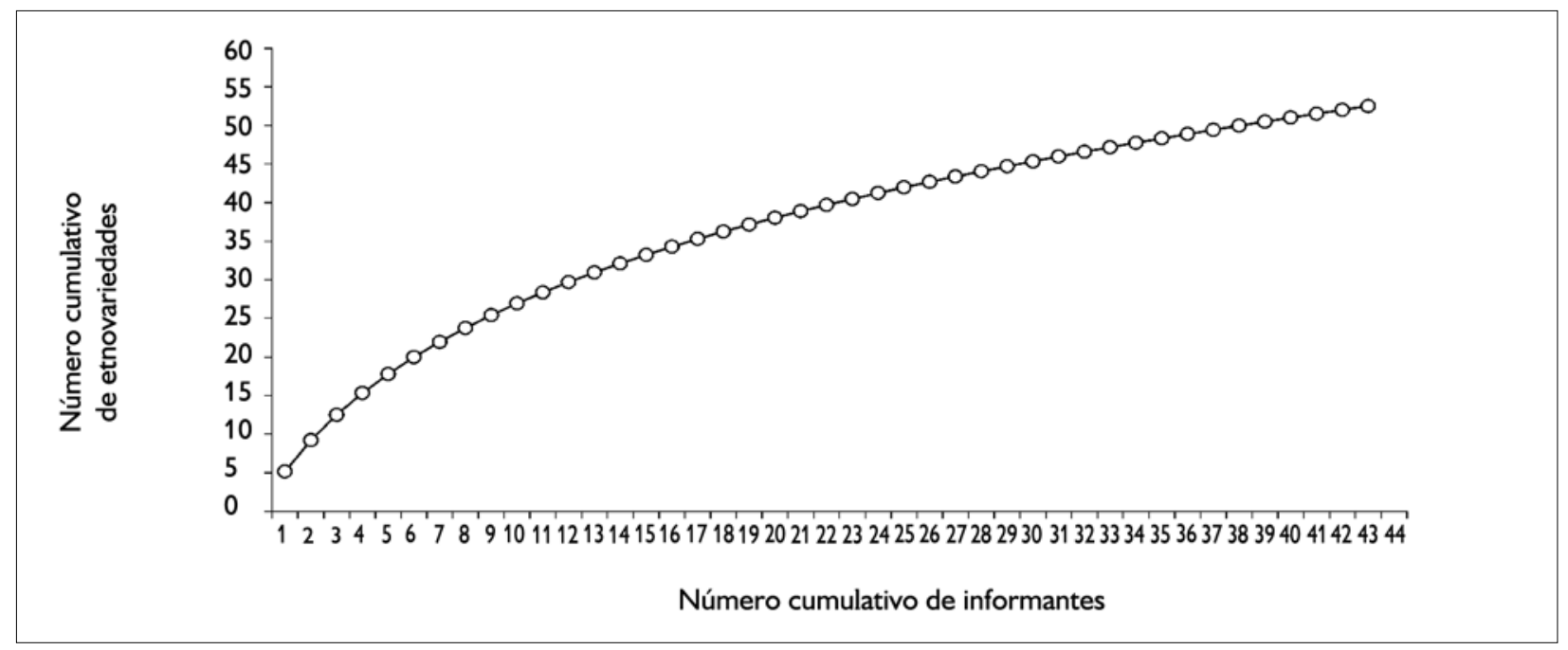

Figura 2. Curva de rarefação para as etnovariedades cultivadas por 44 informantes na Gleba Nova Olinda I, estado do Pará, Brasil.

consumo, sendo frequente encontrar no comércio local o uso de corante para reforçá-la. Martins (2005), Heckler e Zent (2008) e Lima et al. (2012) ressalvaram a importância desses aspectos morfológicos para a diferenciação varietal nos sistemas de etnoclassificação, sendo a coloração dos tubérculos caráter predominante e ressaltado nos trabalhos.

Os dados sobre a caracterização das etnovariedades pelos agricultores locais podem revelar aspectos da magnitude desta cultura agrícola na comunidade. A riqueza varietal, de certa forma, é expressa nas nomeações, havendo diferentes maneiras de se interpretar esse vínculo cultural e ecológico. De acordo com Emperaire (2005), as nomeações podem apontar detalhes sobre o acúmulo cultural da comunidade a respeito desse recurso e sua temporalidade no espaço sociocultural como meio de produção e base de sustentação alimentar. Nomeações genéricas e específicas, com maior detalhamento das variedades, apontam características relevantes sobre o quão perene encontra-se um agrupamento humano em um ambiente. Geralmente, grupos de ocupação recente imprimem nomeações mais superficiais (com referência a cores e a caracteres morfológicos) e agrupamentos humanos mais antigos produzem sistemas de nomeações mais ricos, o que normalmente também significam riqueza genética. Os dados coletados na Gleba Nova Olinda I expressam essa característica temporal no acúmulo de práticas agrícolas tradicionais amazônicas, cujas nomeações estão carregadas de referências ecológicas locais e com relevante riqueza varietal.

\section{OS ROÇADOS E A OBTENÇÃO DE MANDIOCAS}

Nas comunidades estudadas, a área total cultivada é de, aproximadamente, 522,5 ha, dos quais $63 \%$ são destinados ao cultivo de $M$. esculenta. Em algumas comunidades, a mandioca corresponde a mais de 70\% da área cultivada, sendo que na comunidade São José do Progresso ocupa mais de 90\%. Esta última é uma comunidade indígena da etnia Borari.

A manutenção dos recursos genéticos da mandioca decorre do cultivo em roças, geralmente estabelecidas na forma de policultivos. Nestes sistemas, a mandioca divide o espaço com espécies como banana (Musa sp.), jerimum (Cucurbita sp.), milho (Zea mays L.), feijão (Phaseolus vulgaris L.), arroz (Oryza sativa L.), batata (Ipomoea batatas (L.) Lam.) e cana-de-açúcar (Saccharum officinarum L.).

Nos roçados, os arranjos de plantio são ora espacialmente organizados, a exemplo do plantio 'de carreira', ora aleatórios, denominados de plantio 'atrapalhado' (Figura 4). O plantio 'de carreira' favorece a produção mais

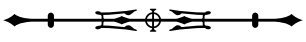


Tabela 2. Comentários locais sobre etnovariedades de mandioca cultivadas em roçados de comunidades da Gleba Nova Olinda I, estado do Pará, Brasil. NI: não informado.

(Continua)

\begin{tabular}{|c|c|c|c|}
\hline Etnovariedade & Cor da batata & $\begin{array}{l}\text { Referencial para } \\
\text { a nomeação }\end{array}$ & Comentário local \\
\hline Açaí & Branca & Palmeira & $\begin{array}{l}\text { Pau preto, folha bem roxa e miudinha. É direita } \\
\text { [não tem galhos] e a batata é branca. }\end{array}$ \\
\hline Acari & Amarela & Peixe & $\begin{array}{l}\text { Pau preto, bem comprido e não dá galho, } \\
\text { folhas verdes, batata amarela. }\end{array}$ \\
\hline \multirow{2}{*}{ Achada } & Branca & \multirow{2}{*}{ Origem } & $\begin{array}{l}\text { Mandioca branca e rendosa; folhas largas, quase } \\
\text { idênticas à Coraci. O pau é roxo e a árvore é baixa. }\end{array}$ \\
\hline & Vermelha & & $\begin{array}{c}\text { A batata e a casca são vermelhas, a árvore é preta } \\
\text { e as folhas, verdes e grandes. } \\
\text { A farinha é branca, meio creme. }\end{array}$ \\
\hline Arrouba & Branca & Outro & $\begin{array}{l}\text { Batata branca, árvore branca, folhas verdes. } \\
\text { A farinha é bem branquinha, a casca, branca. }\end{array}$ \\
\hline \multirow{3}{*}{ Atrapalhadinha } & Amarela & \multirow{3}{*}{ Arquitetura da planta } & $\begin{array}{c}\text { Maniva baixinha e com galhinhos atrapalhadinhos. } \\
\text { Batata amarela; folhinha roxa. }\end{array}$ \\
\hline & Branca & & As folhas são finas e roxas. \\
\hline & $\mathrm{NI}$ & & $\begin{array}{l}\text { Maniva toda doida; uns galhos por aqui, outros para cá } \\
\text { Suas folhas são mais fininhas que as da Jaraqui. }\end{array}$ \\
\hline Baixinha & Amarela & Arquitetura da planta & A planta é baixa. \\
\hline Brebe & Amarela & Outro & Massa amarela, folhas meio roxas e meio finas. \\
\hline Brebezolhuda & Amarela & Atributo organoléptico & $\begin{array}{l}\text { Batata bem amarelinha, árvore branca e folhas cor de } \\
\text { cinza. A farinha é amarela e a casca é vermelha. }\end{array}$ \\
\hline Buriti & Amarela & Palmeira & $\begin{array}{l}\text { Não tem galho embaixo, só ém cima. Pau amarelo, } \\
\text { mandioca bem amarela. É do pau comprido. }\end{array}$ \\
\hline Caroço & Amarela & Atributo morfológico & $\begin{array}{c}\text { Pauzinho preto, toda galhuda e assanhada. } \\
\text { A mandioca é cheia de nós, vãos, assim como o pau. } \\
\text { É amarela. Batata e casca são amarelas; } \\
\text { a árvore é azul; as folhas são verdes pequenas; } \\
\text { a farinha é creme. }\end{array}$ \\
\hline \multirow{2}{*}{ Cavalo } & Vermelha & \multirow{2}{*}{ Fauna } & A maniva é bem vermelha e a folha bem verde. \\
\hline & Amarela & & - \\
\hline \multirow{4}{*}{ Coraci } & Amarela & \multirow{4}{*}{ Outro } & $\begin{array}{l}\text { Batata bem amarela e rendosa, árvore azul, } \\
\text { bem zolhuda, folhas verdes; a farinha não é muito } \\
\text { amarela nem branca... É boa, casca branca. }\end{array}$ \\
\hline & Branca & & $\begin{array}{l}\text { É uma mandioca branca mais rendosa; folhas iguais } \\
\text { às da Achada, o pau... é difícil de explicar. A árvore é } \\
\text { comprida. A casca é roxa, o pau é amarelo. }\end{array}$ \\
\hline & Clara & & - \\
\hline & Creme & & - \\
\hline
\end{tabular}


Tabela 2.

(Continua)

\begin{tabular}{|c|c|c|c|}
\hline Etnovariedade & Cor da batata & $\begin{array}{l}\text { Referencial para } \\
\text { a nomeação }\end{array}$ & Comentário local \\
\hline Douradinha & Amarela & Atributo organoléptico & Por sua massa ser bem amarela. \\
\hline Goela de jacu & Amarela & Pássaro & $\begin{array}{l}\text { Batata bem amarelinha. Árvore cinzenta, folhas roxas. } \\
\text { Farinha amarelinha e casca bem vermelhinha. }\end{array}$ \\
\hline $\begin{array}{l}\text { Inajazinho } \\
\text { (ou najazinho) }\end{array}$ & Amarela & Palmeira & $\begin{array}{l}\text { Pequena, não cresce. [A folhagem] faz aquela roda; } \\
\text { pauzinho branquicento e mandioca bem amarela. }\end{array}$ \\
\hline Inambu (ou nambu) & Branca & Pássaro & $\begin{array}{l}\text { Olhos grandes e folhas largas. A batata é branca e } \\
\text { rendosa; produz com seis meses. }\end{array}$ \\
\hline Jaboti & Branca & Quelônio & $\begin{array}{c}\text { Batata branca, árvore preta, folhas verdes e casca } \\
\text { vermelha. É rendosa. A farinha é creme. }\end{array}$ \\
\hline Jaraqui & Amarela & Peixe & $\begin{array}{l}\text { Pau vermelho e as bracinhas da maniva são brancas; } \\
\text { folhas verdes, mandioca bem amarela. } \\
\text { Batata bem amarela, árvore amarela, } \\
\text { é rendosa e a farinha é amarela; } \\
\text { folhas verdes; casca amarela. }\end{array}$ \\
\hline Jaraqui amarelo & Amarela & Peixe & - \\
\hline Jaraqui preto & Amarela & Peixe & Batata amarela, árvore preta e as folhas também. \\
\hline Manicuera pretinha & $\mathrm{NI}$ & - & Maniva com caule pretinho na parte de baixo. \\
\hline Maria Augusta & Amarela & Origem & $\begin{array}{l}\text { Batata bem amarela, árvore bem direita, } \\
\text { as folhinhas só se dão bem em cima. } \\
\text { A casca é esturricada. A farinha é amarela. }\end{array}$ \\
\hline Milagrosa & Branca & Outro & Maniva [caule] branca e mandioca branca. \\
\hline \multirow{2}{*}{ Munguba } & Amarela & Árvore & Pau branco; folhas bem roxas; batata bem amarelinha. \\
\hline & Branca & Árvore & - \\
\hline Papagaio & Amarela & Pássaro & É bem verde e a maniva é amarela. \\
\hline Passarinho & Amarela & Pássaro & $\begin{array}{c}\text { Batata amarela, árvore azul, folhas verdes, farinha } \\
\text { amarela, casca vermelha. É rendosa. }\end{array}$ \\
\hline \multirow[t]{2}{*}{ Piaba } & Amarela & Peixe & $\begin{array}{l}\text { Árvore branca e folhas brancas. A casca da } \\
\text { batata é branca, mas a massa é amarela. }\end{array}$ \\
\hline & Clara & Peixe & - \\
\hline Pinajé & Branca & Outro & $\begin{array}{c}\text { É uma mandioca branca mais rendosa. } \\
\text { A maniva [caule] é cor de vinho, } \\
\text { a folha é fina, idêntica à da Sardinha. }\end{array}$ \\
\hline Pingo de ouro & Amarela & Atributo organoléptico & $\begin{array}{c}\text { A batata é amarela, a maniva [caule] é branca e } \\
\text { não é rendosa. A farinha é amarela. }\end{array}$ \\
\hline \multirow{2}{*}{ Pretona } & Amarela & \multirow{2}{*}{ Atributo organoléptico } & $\begin{array}{l}\text { Pau direito; folhas pretas, roxas; mandioca branca. } \\
\text { Batata e casca são amarelas. }\end{array}$ \\
\hline & Branca & & $\begin{array}{l}\text { Árvore azul, folhas redondas e pequeninas. } \\
\text { A farinha é bem creme. }\end{array}$ \\
\hline
\end{tabular}

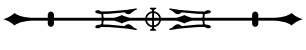




\begin{tabular}{|c|c|c|c|}
\hline Etnovariedade & Cor da batata & $\begin{array}{l}\text { Referencial para } \\
\text { a nomeação }\end{array}$ & Comentário local \\
\hline São José & Branca & Origem & $\begin{array}{l}\text { Batata branquicenta e rendosa. Farinha creme. } \\
\text { Árvore branca e ramalhuda; casca branca. }\end{array}$ \\
\hline \multirow{3}{*}{ Sardinha } & Amarela & Peixe & $\begin{array}{l}\text { Pauzinhos finos, ramalhudos; folhas bem finas, } \\
\text { galhinhos brancos, mandioca branca. } \\
\text { Essa é do tipo branca. }\end{array}$ \\
\hline & Branca & Peixe & $\begin{array}{c}\text { Maniva branca e folhas miúdas e finas, pau } \\
\text { vermelho branquicento; mandioca amarela. } \\
\text { Madeira mais amarela. É rendosa. }\end{array}$ \\
\hline & Branco amarelado & Peixe & - \\
\hline Seis meses & Branca & Atributo de produção & $\begin{array}{l}\text { Batata branca, árvore branca e folhas verdes. } \\
\text { A farinha é bem branquinha; a casca é vermelha. }\end{array}$ \\
\hline Tambaqui & Amarela & Peixe & $\begin{array}{l}\text { Árvore bem direita, com folhas bem em cima; } \\
\text { não tem galho nem nada. Batata bem amarelinha. }\end{array}$ \\
\hline Tartaruguinha & Branca & Quelônio & $\begin{array}{l}\text { Árvore azul, batata branca e folhas verdes. A farinha } \\
\text { não é branca nem amarela; casquinha branca. }\end{array}$ \\
\hline Tucumã & Amarela & Palmeira & $\begin{array}{l}\text { Dá bem alta. Pau vermelho, bracinhos brancos, } \\
\text { folhas verdes só em cima. Mandioca amarelinha. } \\
\text { A farinha dela sozinha é bem amarelinha, parece } \\
\text { até que tem cor [corante], mas não é... }\end{array}$ \\
\hline
\end{tabular}

elevada por unidade de área e a obtenção de excedente para a comercialização da farinha (Figura 4A). A área com plantio 'atrapalhado' (Figuras 4B e 4C), além de contribuir para a produção comercial, tem papel importante, pois é incrementada com espécies essenciais para a diversificação da dieta local e, consequentemente, para a segurança alimentar das famílias.

A arquitetura dos roçados, implantados sob o sistema de corte e queima, chega a ser reconhecida como prática unificadora da cultura rural brasileira em cultivos tradicionais (Martins, 2005). A grande riqueza de técnicas agronômicas deve-se ao êxito em implantar cultivos com características ecológicas diferentes e compor um sistema diversificado de espécies e variedades em um mesmo espaço (Martins, 2005). O papel das roças nas estratégias de forrageamento amazônidas está intimamente relacionado aos aspectos culturais e agrícolas desenvolvidos em torno de um conjunto de espécies chave, onde a mandioca tem papel de destaque (Adams et al., 2008). A diversidade varietal nas comunidades da Gleba Nova Olinda I decorre do acúmulo local no desempenho do cultivo e manejo das roças, bem como da obtenção de material nas redes locais de troca e manutenção de coleções particulares.

A troca de material afeta diretamente a riqueza varietal e decorre da especificidade produtiva das etnovariedades. Por exemplo, as mandiocas Inajazinho, Coraci, Sardinha, Arrouba, Seis-meses e Jaraqui são especialmente mencionadas como ótimas fornecedoras de goma, sendo que a Coraci também é boa para extração do tucupi. As indicadas para a produção de farinha são principalmente Coraci, Sardinha, Jaraqui e Achada, por apresentarem os principais atributos

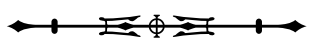




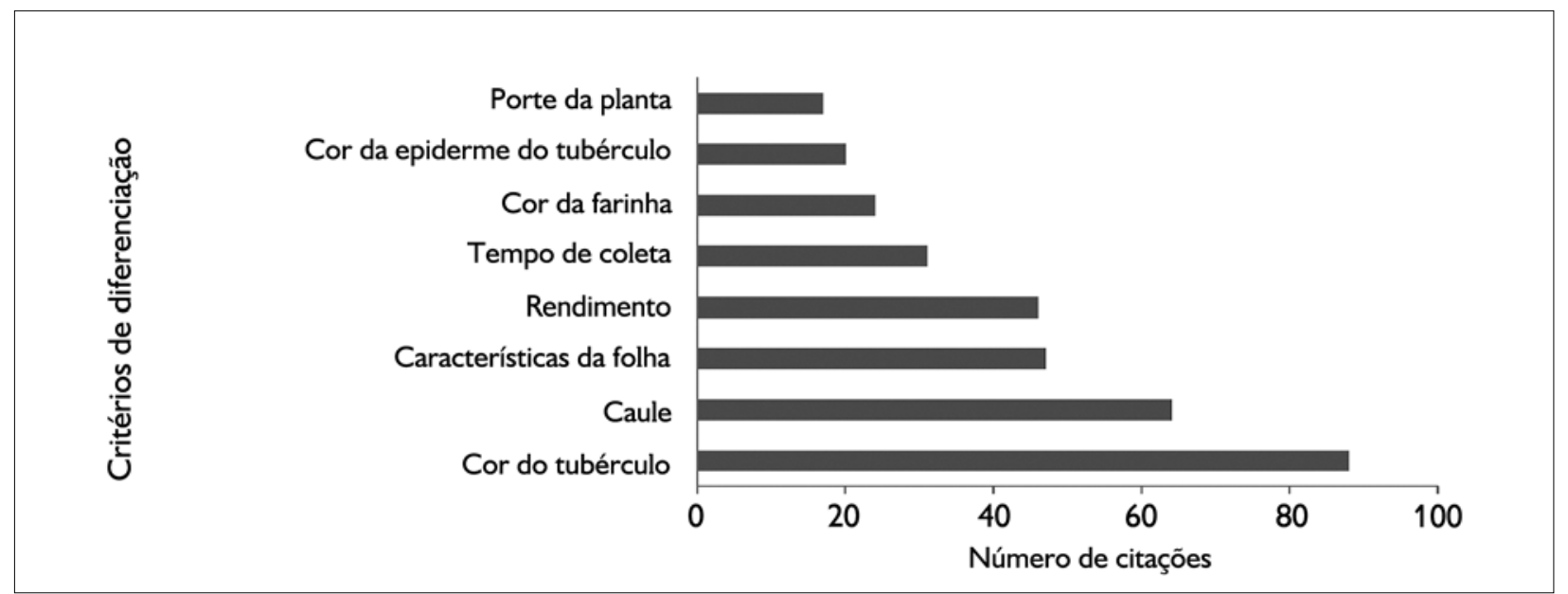

Figura 3. Atributos observados pelos informantes para a diferenciação das etnovariedades de mandioca na Gleba Nova Olinda I, estado do Pará, Brasil.

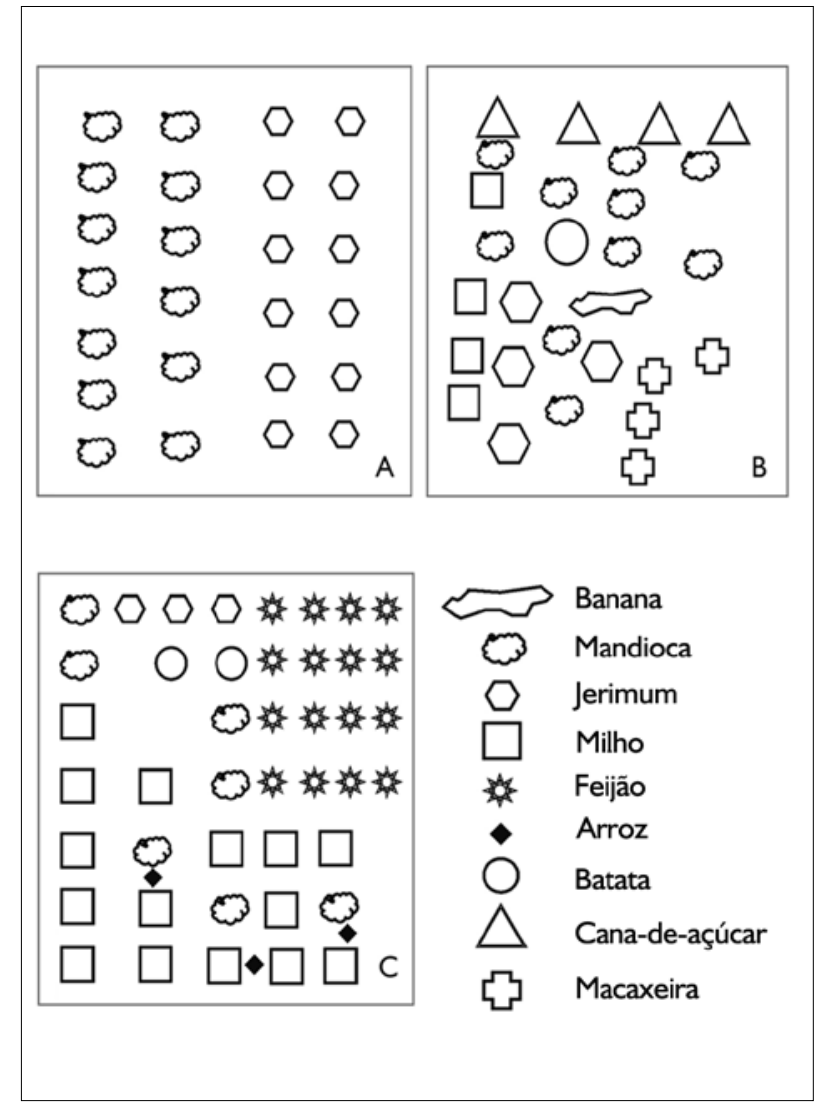

Figura 4. Croqui de três tipos de arranjos espaciais de cultivo utilizados nos roçados da Gleba Nova Olinda I. A) Cultivo em carreira; B) Cultivo atrapalhado; C) Cultivo em carreira com mandioca em cultivo atrapalhado. desejáveis de uma boa mandioca: tubérculos rendosos e de coloração amarela. Socialmente, a obtenção dos propágulos, 'manivas', ocorre tanto entre familiares como entre amigos, de forma intra e intercomunitária.

Na Figura 5, é apresentada a abrangência da rede de troca entre as comunidades. Apesar de ter sido evidenciado nas entrevistas que o número de etnovariedades trocadas entre comunidades é baixo, ressalta-se que a diversidade atualmente estabelecida é resultado de um longo processo de acúmulo de material, na maioria das vezes, perdendose, ao longo do tempo, na memória local. A rede de trocas identificada vai além dos limites das comunidades estudadas, alcançando um raio de pelo menos $118 \mathrm{~km}$, considerando-se a relação estabelecida com o ponto mais distante referenciado no trabalho, o município de Parintins, Amazonas. Foi deste local que uma comunitária de Vista Alegre conseguiu a etnovariedade Sardinha.

As formas de compartilhamento identificadas são típicas de relações de parentesco e compadrio, muito presentes em redes sociais no meio rural amazônico. Essa característica da rede local de trocas do material genético da mandioca também foi constatada em outras pesquisas. No entanto, o caso estudado não chega a constituir uma rede complexa, como ocorre em grupos

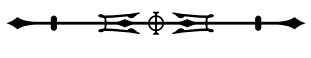




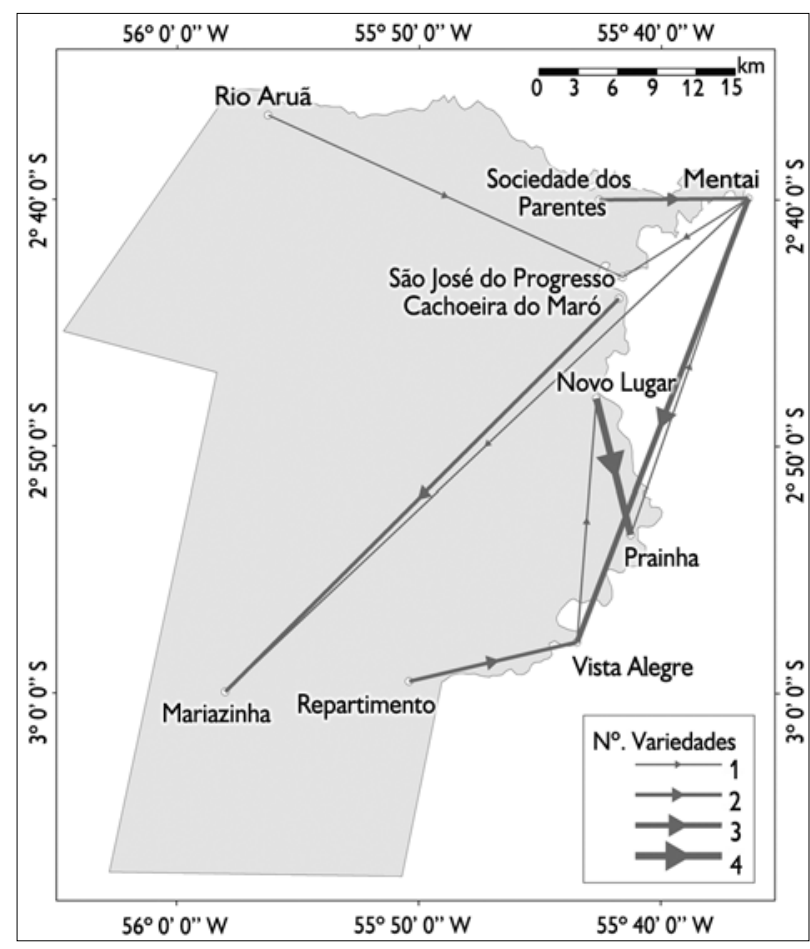

Figura 5. Fluxo de material genético de Manihot esculenta Crantz relacionado às comunidades Fé em Deus, Mariazinha, Mentai, Novo Lugar, Prainha, Repartimento, São José do Progresso e Vista Alegre, na Gleba Nova Olinda I, estado do Pará, Brasil.

da etnia Tukano, na qual a ampliação da diversidade varietal faz parte do ritual matrimonial: a primeira roça estabelecida pela esposa recebe material fornecido por sua sogra (Chernela, 1986; Emperaire, 2002).

De maneira geral, por meio de diversos mecanismos de trocas, as etnovariedades de mandioca estão diretamente ligadas à manutenção de uma rede social, que vai além da simples permuta de recursos genéticos. Ao incluí-las, essa rede interfere na conservação de um patrimônio essencial para a segurança alimentar das comunidades. Tal prática amplia a diversidade varietal nos roçados, contribuindo para a promoção da resistência dos plantios. O empobrecimento de variedades em roçados aumenta a probabilidade de perdas via ataque de pragas e doenças, enquanto que a riqueza de variedades é favorável ao cultivo, podendo oferecer diferentes formas de resistência dentro dos roçados (Faraldo et al., 2000).
Sobre a manutenção da diversidade varietal em roçados, Peroni et al. (1999) explicam que o agricultor a promove de forma consciente ou inconsciente, mas, de toda forma, sempre contribui para a manutenção da variação de características produtivas, selecionadas de acordo com as circunstâncias. $\bigcirc$ aumento da frequência do cultivo de uma etnovariedade em uma roça pode estar associado à sua adaptação a um tipo de solo ou à qualidade da farinha produzida. De qualquer maneira, de forma consciente ou não, é interessante a conservação de germoplasmas particulares nas propriedades locais, contendo a variação de outras características que podem ser úteis no futuro.

A diversidade varietal dessa espécie tem chamado a atenção de vários autores sobre o papel do conhecimento e do manejo sob domínio de comunidades tradicionais para o futuro da agrobiodiversidade (Emperaire e Peroni, 2007; Heckler e Zent, 2008; Peroni et al., 2008; Fraser, 2010). A mandioca vem se consolidando como modelo para a discussão de novas experiências de conservação da biodiversidade, associada ao conhecimento tradicional na Amazônia (Emperaire, 2005; Emperaire e Peroni, 2007). O reconhecimento da importância desta espécie para a agrobiodiversidade amazônica sugere o investimento de mais estudos sobre etnovariedades presentes em comunidades tradicionais, principais mantenedoras do germoplasma amazônico da espécie, por meio do cultivo em roçados (Emperaire, 2002).

A conservação da agrobiodiversidade tem sido pensada como dependente de outras estratégias, além da conservação ex situ e in situ. Emperaire e Peroni (2007) explicam que, ao se compreender o fato de as variedades resultarem de um processo de construção local, devese atentar para a adoção de novos critérios voltados à manutenção dos recursos genéticos e que valorizem o aspecto cultural inerente à agrobiodiversidade. Dessa forma, destacam que a conservação on farm vem a ser uma proposta pertinente por preconizar o manejo sustentável da diversidade genética de variedades dentro dos sistemas produtivos dos agricultores tradicionais.

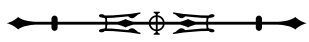




\section{CONSIDERAÇÕES FINAIS}

A agrobiodiversidade mantida em algumas comunidades rurais amazônicas tem fortes características para subsidiar estratégias de conservação on farm. Nas comunidades estudadas, existem condições de apoio a essa estratégia de conservação para a mandioca, em função, principalmente, das seguintes características: significante riqueza de etnovariedades, com diversos fins produtivos (farinha, goma e tucupi); associação deste cultivo com outras espécies da agrobiodiversidade da região; existência de importante rede de troca de material, intra e intercomunitária.

O reconhecimento dos saberes tradicionais sobre esse recurso agrobiológico deve ser considerado em ações de valorização do patrimônio cultural local. A diversidade de etnovariedades mantida nos roçados destas comunidades deve ser avaliada não apenas pela ótica de uma atividade econômica que se sobressai, mas como prática cultural, que deve ser reconhecida e valorizada por meio de novas formas de apoio às comunidades rurais.

A compreensão dos aspectos socioculturais e ecológicos relacionados à conservação da mandioca tem recebido atenção no campo científico, mas as ferramentas políticas para a valorização desses sistemas devem ser fortalecidas. $\bigcirc$ fato é que as inciativas para ampliação do conhecimento sobre a sabedoria das populações amazônidas no manejo de agroecossistemas vêm se consolidando, mas a repercussão em benefícios políticos para as comunidades ainda é inexpressiva, devendo ser alcançada, considerando esforços das diferentes esferas governamentais.

\section{REFERÊNCIAS}

ADAMS, C.; MURRIETA, R.; SIQUEIRA, A.; NEVES, W.; SANCHES, R. O pão da terra: da invisibilidade da mandioca na Amazônia. In: ADAMS, C.; MURRIETA, R.; NEVES, W. (Eds.). Sociedades caboclas amazônicas: modernidade e invisibilidade. São Paulo: Annablume, 2008. p. 295-321.

AMOROZO, M. C. M. Management and conservation of Manihot esculenta Crantz germplasm by traditional farmers in Santo Antônio do Leverger, Mato Grosso State, Brazil. Etnoecológica, v. 4, n. 6 , p. $69-83,2000$.
CHERNELA, J. M. Os cultivares de mandioca na área do Uaupés (Tukâno). In: RIBEIRO, B. G. (Ed.). Suma etnológica brasileira: Etnobiologia. Petrópolis: Vozes, 1986. p. 151-158.

EMPERAIRE, L. A biodiversidade agrícola na Amazônia brasileira: recurso e patrimônio. Revista do Instituto do Patrimônio Histórico e Artístico Nacional, v. 32, p. 23-35, 2005.

EMPERAIRE, L. Agrobiodiversidade em risco: o exemplo das mandiocas na Amazônia. Ciência Hoje, v. 32, n. 187, p. 28-33, 2002.

EMPERAIRE, L. Entre selva y ciudad: estrategias de producción en el Rio Negro Medio (Brasil). Bulletin de l'Institut Français d'Etudes Andines, v. 29, n. 2, p. 215-232, 2000.

EMPERAIRE, L.; PERONI, N. Traditional management of agrobiodiversity in Brazil: a case study of manioc. Human Ecology, v. 35, n. 6, p. 761-768, 2007.

EMPRESA BRASILEIRA DE PESQUISA AGROPECUÁRIA (EMBRAPA). Mandioca: o pão do Brasil (Manioc: le pain du Brésil). Brasília: EMBRAPA, 2005.

FARALDO, M. I. F.; SILVA, R. M.; ANDO, A.; MARTINS, P. S. Variabilidade genética de etnovariedades de mandioca em regiões geográficas do Brasil. Scientia Agricola, v. 57, n. 3, p. 499-505, 2000.

FRASER, J. Caboclo horticulture and Amazonian Dark Earths along the Middle Madeira River, Brazil. Human Ecology, v. 38, n. 5, p. 651-662, 2010.

FUNDAÇÃO NACIONAL DO ÍNDIO (FUNAI). Despacho do Presidente, 7 de outubro de 2011. Diário Oficial da União, Brasília, seção 1, n. 195, p. 36, 10 out. 2011.

HANAZAKI, N.; TAMASHIRO, J. Y.; LEITÃO-FILHO, H. F.; BEGOSSI, A. Diversity of plant uses in two Caiçara communities from the Atlantic Forest coast, Brazil. Biodiversity \& Conservation, v. 9, n. 5, p. 597-615, 2000.

HECKLER, S.; ZENT, S. Piaroa manioc varietals: hyperdiversity or social currency? Human Ecology, v. 36, n. 5, p. 679-697, 2008.

INSTITUTO BRASILEIRO DE GEOGRAFIA E ESTATÍSTICA (IBGE). Sistema IBGE de Recuperação Automática (SIDRA). 2012. Disponível em: <http://www.sidra.ibge.gov.br>. Acesso em: 12 fev. 2012.

KERR, W. E.; CLEMENT, C. R. Práticas agrícolas de consequências genéticas que possibilitaram aos índios da Amazônia uma melhor adaptação às condições ecológicas da região. Acta Amazonica, v. 10, n. 2, p. 251-261, 1980.

LIMA, D.; STEWARD, A.; RICHERS, B. Trocas, experimentações e preferências: um estudo sobre a dinâmica da diversidade da mandioca no Médio Solimões, Amazonas. Boletim do Museu Paraense Emílio Goeldi. Ciências Humanas, v. 7, n. 2, p. 371 396, 2012. 
MARTINS, P. S. Dinâmica evolutiva em roças de caboclos amazônicos. Estudos Avançados, v. 19, n. 53, p. 209-220, 2005.

NASSAR, N. M. A. Wild and indigenous cassava, Manihot esculenta Crantz diversity: an untapped genetic resource. Genetic Resources and Crop Evolution, v. 54, n. 7, p. 1523-1530, 2007.

ORGANIZAÇÃO DAS NAÇÕES UNIDAS (ONU). Convenção sobre Diversidade Biológica. Rio de Janeiro, jun. 1992. Disponível em: <http://www.mma.gov.br/biodiversidade/convencao-dadiversidade-biologica $>$. Acesso em: 12 jun. 2012.

PARÁ, Governo do Estado. Instituto de Desenvolvimento Florestal do Pará. Projeto de desenvolvimento comunitário: fortalecimento da economia agroflorestal e extrativista das comunidades na Gleba Nova Olinda. Belém: IDEFLOR, 2009.

PERONI, N.; ARAUJO, H. F. P.; HANAZAKI, N. Métodos ecológicos na investigação etnobotânica e etnobiológica: o uso de medidas de diversidade e estimadores de riqueza. In: ALBUQUERQUE, U. P.; LUCENA, R. F. P.; CUNHA, L. V. F. C. (Orgs.). Métodos e técnicas na pesquisa etnobotânica. Recife: NUPEEA, 2008. p. 199-225.
PERONI, N.; MARTINS, P. S.; ANDO, A. Diversidade inter- e intraespecífica e uso de análise multivariada para morfologia da mandioca (Manihot esculenta Crantz): um estudo de caso. Scientia Agricola, v. 56, n. 3, p. 587-595, 1999.

ROBERT, P.; LÓPEZ GARCÉS, C. L.; LAQUES, A. E.; COELHOFERREIRA, M. A beleza das roças: agrobiodiversidade MebêngôkreKayapó em tempos de globalização. Boletim do Museu Paraense Emílio Goeldi. Ciências Humanas, v. 7, n. 2, p. 339-369, 2012.

SANTILLI, J. F. R. Agrobiodiversidade e direito dos agricultores. 2009. 409 f. Tese (Doutorado em Direito) - Pontifícia Universidade Católica do Paraná, Curitiba, 2009. 
